\title{
Effect of River Training Project on Hydrodynamics Flow Circumstances by 2D Finite Element Numerical Model
}

\author{
B. Zou ${ }^{1}$, D. F. $\mathrm{Li}^{1,2 *}$, H. J. Hu${ }^{1}$, H. W. Zhang ${ }^{3}$, L. H. Lou ${ }^{4}$, M. Chen ${ }^{1}$, Z. Y. Lv ${ }^{2}$ \\ ${ }^{1}$ Department of Hydraulic Enginecring. Zhejiang Water Conservancy and Hydropower College, \\ Hangzhou 310018, China \\ ${ }^{2}$ Institute of Fluid Mechanics, Beijing University of Aeronautics and Astronautics, Beijing 100083, \\ China \\ ${ }^{3}$ Department of Hydraulic Engineering, Tsinghua University, Beijing 100084, China \\ ${ }^{4}$ Bureau of Water Resource of Kecheng District, Quzhou, Zhejiang, Beijing 324000, China \\ Email: lidongfeng998@163.com
}

\begin{abstract}
Based on the verified two dimensional(2D) finite element model for river flow simulation, the effect of estuary training levees on the water flow and sediment movement in the Yellow River estuary is analyzed. For disclosing the effect of setting the two training levees on the flow and sediment motion, the calculation and analysis for the two projects, (one is no levees, the other is setting up two no levees) are given. The results show that when setting up two training levees, water flow is bound by levees and the water flows become more concentrated. As a result, velocity increases in the main channel, sediment carrying capacity of water flow increases correspondingly.

Table shows the position and point numbers (named respectively No.2260, No.2201, No.2242, No.2283 ) and magnitude comparison of maximum sediment concentration in the condition of setting up levees with that of no levees. It is found that the point of the maximum sediment concentration go outside from No.2242 to No.2283, the distance of the two points is $920 \mathrm{~m}$ long. So setting up levees can play a very effective role.
\end{abstract}

\begin{tabular}{lccc}
\multicolumn{3}{c}{ Table 1 The position and point } & numbers comparison of maximum sediment concentration \\
\hline \multirow{3}{*}{ Spring time } & Items & Mesh points numbers & Sediment concentration $\left(\mathrm{kg} / \mathrm{m}^{3}\right)$ \\
& no levees & 2160 & 9.6 \\
\multirow{2}{*}{ Ebb time } & setting up levees & 2201 & 10.5 \\
& no levees & 2242 & 11.3 \\
& setting up levees & 2283 & 13.5 \\
\hline
\end{tabular}

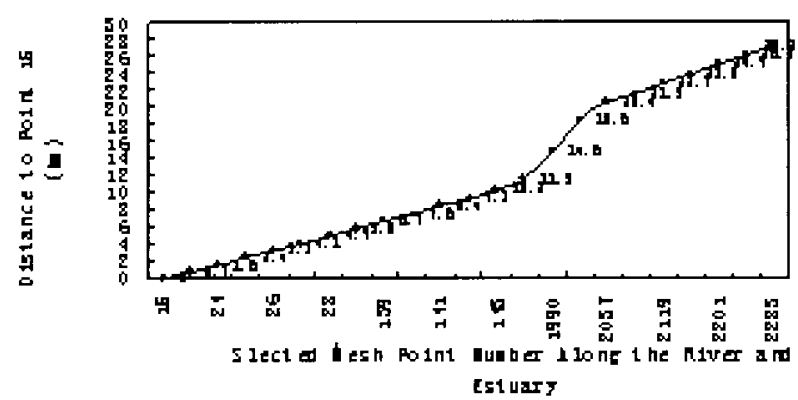

Figure: Distance of selected mesh point number along the river and estuary to point No.15 